\title{
BIBLIOGRAFIA
}

\section{Notas Bibliográficas Sobre la Obra Poética de D. José María Roa Bárcena}

I

\section{RECTIFICACIONES}

SI bien se considera a don José María Roa Bárcena (1827-1908) D como uno de los primeros cuentistas mexicanos, la crítica de nuestros tiempos no juzga al ilustre jalapeño como uno de los grandes poetas nacionales. $Y$ no pretendemos afirmar que la poesía de don José María sea superior a la de tantos otros bardos cuya sola evocación sería desventajosa para Roa. El autor de las Leyendas mexicanas pulsa la lira con la moderación que le fué tan característica tanto en su vida como en su obra: gusto clásico, sobrio y sencillo es el de Roa Bárcena, por afinidad, por atavismo, por tradicionalismo.

La obra poética juvenil de don José María se halla dispersa en diferentes revistas de 1843 a 1851, como El Museo Mexicano, El Album Mexicano, El Espectador de México, El Locomotor, La Cartera Veracruzana y El Veracruzano. Entre las otras revistas y publicaciones periódicas que dieron cabida a sus versos después de mediados del siglo XIx se cuentan La Cruz, La Sociedad, El Renacimiento, La Voz de México, El Mensajero Católico, El Tiempo, La $V$ oz de San Luis, Revista Azul, Revista Nacional de Letras y Ciencias y las Memorias de la Academia Mexicana. 
El primer tomo de poesías que publicó fué el de Flores de mayo, o sea el mes de María, en prosa y en verso, que apareció en 1856, con una segunda edición de 1909, rarísimas ambas ediciones. En $L a$ Cruz, ese famoso órgano de las ideas conservadoras donde tanto colaborara Roa, se publicó un artículo bibliográfico fechado el 26 de noviembre de 1856 y firmado por los "Redactores de $L a$ Cruz", en que se da noticia no sólo de la aparición del tomito en cuestión, sino que se reproduce la meditación, la oración y la poesía del día $1^{\circ}$ de mayo, además de la introducción del libro. ${ }^{1}$ Se dice ser un tomo en 16\%, publicado en México por Escalante y Cía. De la segunda edición tenemos noticia por medio de don Ignacio Montes de Oca, obispo de San Luis Potosí y amigo íntimo de Roa Bárcena, así como su biógrafo más autorizado, en la "Introducción" a las Obras poéticas de nuestro bardo. ${ }^{2}$

En 1859 da a la luz su tomo de Poesías líricas, que se publicó tal vez poco después del 20 de agosto del mismo año, fecha que reza en la introducción, donde confiesa Roa que el único móvil de la publicación de sus versos fué "el natural deseo de mi familia y las escitativas de algunos amigos". ${ }^{3}$ Lo dividió en dos partes: composiciones diversas que incluyen las originales y las traducidas a adaptadas, y composiciones religiosas, entre las que se incluyen varias, o tal vez todas, de las ya publicadas en Flores de mayo.

En 1862 aparecieron sus Leyendas mexicanas, cuentos y baladas del norte de Europa, y algunos otros ensayos poéticos, en que se encuentran, además de sus famosas leyendas mexicanas, nuevas traducciones y adaptaciones. En el año de 1865 parece que se publicó una segunda edición, aunque hasta ahora ningún crítico la menciona. Rebuscando aquí y allá dimos con un articulillo en La Sociedad, en que se dice que Agustín Masse, propietario de la Librería Mexicana, había publicado recientemente una obra de Roa Bárcena con el título de Leyendas mexicanas, y se anuncia que El Correo de Ultramar empezará a publicar "Xóchitl" para dar a sus lectores una muestra de estas leyendas. ${ }^{4} \mathrm{Y}$ en otro número de La Sociedad aparece en la sección de anuncios de la Librería Mexicana un tomo de Leyendas en $8^{\circ}$, "de cerca de 400 páginas, en buen papel y perfectamente impreso y empastado en tafilete", ${ }^{5}$ anuncio que se repite con bastante regularidad por algún tiempo en dicho periódico. Es casi seguro que 
se trata de una nueva edición, ya que de 1862 a 1865, fecha del artículo de La Sociedad, median tres años, plazo demasiado largo para que se considere reciente la publicación, sobre todo cuando va a reproducirse una de sus mejores leyendas para darla a conocer al público. También hay que recordar que la primera edición de 1862 tiene solamente 364 páginas.

En 1875, en edición de cien ejemplares, sale a la luz pública el tomito de Nuevas poesias. Aunque escrito en 1877 , no es sino hasta 1879 cuando encontramos en edición de 50 ejemplares su poema $V a s-$ co Núñez de Balboa, con una nueva edición en 1880. El crítico colombiano Miguel Antonio Caro reúne en un volumen las Poesías de Diego Fallon y José María Roa Bárcena, en Bogotá, en 1882, colección tomada casi exclusivamente del tomo de Leyendas mexicanas. En edición de 150 ejemplares da don José María a la imprenta sus Ultimas poesías líricas de 1888. También se hallan algunas de sus poesías en la colección de Riva Palacio intitulada El parnaso mexicano, de 1889, pero desgraciadamente le faltan bastantes páginas al ejemplar que examinamos. Aunque escrito en 1851 y ya publicado en parte en La Cruz y totalmente en Poesías líricas, su Diana se da a la estampa separadamente en 1892 en edición de 50 ejemplares; y, con la aparición de las Ultimas poesías líricas, con Apéndice, hasta mediados de 1895, libro que se imprimió después del 30 de junio de dicho año y que no debe confundirse con la edición de 1888 del mismo título, tocan a su fin los tomos de versos publicados durante la vida del poeta. Póstumas son las Flores de mayo en su segunda edición, como ya dejamos anotado, y las Obras poéticas, primer tomo, que publicaron sus hijas en 1913. El segundo tomo de estas obras no llegó a publicarse, según me confesó en 1941 doña Concepción Roa y Villamil, hija del bardo, por la condición azarosa en que se encontraba el país en aquellos tiempos. Más tarde el papel, que ya se tenía comprado para dar a la imprenta este segundo volumen, se perdió.

Muchos son los periódicos y revistas que publicaron versos de Roa en vida y después de su muerte, como ya dijimos; merecieron varios de sus poemas los honores de antología, como ya mostraremos en una bibliografía que preparamos.

Pero tratemos ahora de rectificar algunos de los errores en que han incurrido varios críticos, errores bien disculpables por cierto, 
dado el contado número de ejemplares en casi todas las ediciones: de sus poemas.

Un diccionario enciclopédico dice que las Leyendas mexicanas "tuvieron segunda parte: Cuentos y baladas del norte de Europa; y tercera: Composiciones diversas (Méjico, 1862)". ${ }^{6}$

La enciclopedia Espasa-Calpe hace las tres clasificaciones, dando la fecha de 1862 a dos y dejando sin fechar los Cuentos y baladas del norte de Europa, añadiendo tn tomo de Poesías de 1858, que sin duda es el de 1859. ${ }^{7}$ Parece que los dos diccionarios enciclopédicos confundieron y separaron el título del tomo que se publicó en 1862 , Leyendas mexicanas, cuentos y baladas del norte de Europa, y algunos otros ensayos poéticos.

Julio Cejador y Frauca, en su voluminosa historia literaria, habla de unas Leyendas en verso, Poesías líricas y Leyendas de 1858, de que no tenemos la menor mención y que serán otras ediciones como las de 1859 y de 1862 . Añade unas Ultimas poesías líricas, de 1891, que creemos míticas también. 8

Siguiendo a Cejador y Frauca, Estelle Lutrell da la fecha de 1858 para las Poesías liricas y las Leyendas en verso, y la edición de 1891 de Ultimas poesías líricas. ${ }^{9}$

En un artículo escrito por el investigador norteamericano S. L. Millard Rosenberg sobre la prosa mexicana, se afirma que las leyendas mexicanas "han sido traducidas a varios idiomas". ${ }^{10}$ Por más pesquisas que hicimos no nos fué posible dar con una sola de esas traducciones y nos reservamos, por tanto, el decir que han sido traducidas, hasta no tener otros datos más concretos.

Don Julio Jiménez Rueda, en su excelente Antología de la prosa en México, nos da noticia de unas Poesías de 1858 y 1877 que son, sin duda, las Poesías líricas de 1859 y las Nuevas poesías de 1875 , respectivamente. ${ }^{11}$

En el prólogo que escribió el mismo estudioso profesor Jiménez Rueda a los Relatos, antología que publicara la Universidad Nacional Autónoma en 1941, incluyendo algunos cuentos y biografías de don José María, apunta dicho señor que Roa "reunió sus primeras poesías en el año de 1858". ${ }^{12}$ No dudamos que se hayan reunido en dicho año, pero, como ya dejamos dicho en otra parte, las Poesías líricas, 
que son a las que indudablemente se refiere el historiador de nuestra literatura, son de 1859.

Parece que quien originó este error de la publicación en 1858 del ya tantas veces mencionado tomo de Poesias líricas fué don Victoriano Agüeros, al hablar de los Escritores mexicanos contemporáneos. ${ }^{13}$

En cambio, el erudito González Peña apunta que la Diana se publicó en 1857 , edición que es probable que no exista. ${ }^{14} \mathrm{El}$ crítico mexicano tal vez se refiera a 1851 , fecha en que se escribió este poema narrativo de la juventud de Roa; aunque es cierto que en La Cruz (tomo II, pp. 589-590) se insertó el canto II de la primera parte, pero no se publicó más. En 1859 apareció en su totalidad, y creemos por primera vez, en las Poesías líricas, pp. 93-213. Más tarde, en 1892, se publica separadamente, como ya quedó anotado, para ser reproducida en las Obras poéticas de 1913, pp. 197-332.

En la Bibliografía de la poesía mexicana, de los señores TorresRioseco y Warner, en la lista que se hace de las obras poéticas de don José María notamos la ausencia de las Nuevas poesias de 1875 , de las Ultimas poesías líricas de 1895 y de las ediciones de 1879 y 1880 del Vasco Núñez de Balboa. ${ }^{15}$

Por último, y más recientemente, el erudito Werner Peiser, en la bibliografía de su artículo "El humanismo en la literatura mexicana", nota un tomo de Poesias de Roa Bárcena, de 1889, que sin la menor duda creemos se refiere a las Ultimas poesías liricas de $1888 .^{16}$

En unos ligeros apuntes bibliográficos no viene al caso dar un juicio sobre la obra poética del señor Roa Bárcena, pero hay que observar que, precisamente por el poco conocimiento que se tiene ahora de los versos de tan insigne literato, se le ha sepultado en el panteón del olvido. Las ediciones, poco conocidas, reducidísimas y casi no leídas, contribuyeron no poco a desmoronar el prestigio literario que se había formado don José María Roa Bárcena. Nos limitaremos a señalar que como poeta es Roa, si no grande, sí distinguido. Su misma corrección y razón no le permiten dar rienda suelta a su inspiración: el decoro, y siempre el decoro, fué la norma de su poesía, como lo fué de su viđa. Fué buen poeta, excelente versificador, cualidades insuficientes para sobresalir en la tierra en que los buenos y aun. los grandes poetas abundan. 
(A continuación damos una lista de los tomos de versos solamente, reservándonos para más tarde la bibliografía de los poemas que aparecieron en publicaciones periódicas.)

Flores de mayo, o sea el mes de María, México, Escalante y Cía. (Publicado antes del 26 de noviembre de 1856 , según se afirma en La Cruz, III, pp. 538-542.)

1859

Poesias liricas, Edición de "La Sociedad", México, Imprenta de Andrade y Escalante. 396 páginas. (Con un prólogo de "El autor al lector". Publicado después del 20 de agosto.)

1862

Leyendas mexicanas, cuentos y baladas del norte de Europa, y algunos otros ensayos poéticos, México, Editor, Agustín Masse, Librería Mexicana. 364 páginas.

1865

Leyendas mexicanas, cuentos y baladas del norte de Europa, y algunos otros ensayos poéticos, segunda edición, México, Librería Mexicana (?). (Según La Sociedad, tercera época, tomo v, $\mathrm{N}^{\circ} 748$, lunes 10 de julio de 1856 , p. 3 ; y también el tomo vi, $N^{\circ} 1111$ del miércoles 11 de julio de 1866 del mismo periódico. Tal vez fué Agustín Masse quien publicó esta segunda edición que discutimos en el texto.)

1875

Nuevas poesias, México, Imprenta de Ignacio Escalante, edición de cien ejemplares. 78 páginas.

1879

Vasco Núñez de Balboa, 1877, México, Imprenta de Ignacio Escalante, edịciọn de 50 ejemplares. 50 páginas. 
1880

Vasco Núnez de Balboa, 1877, México, Imprenta de Ignacio Cumplido. 63 páginas.

1882

Poesias de Diego Fallon y José María Roa Bárcena, Bogotá, Librería Americana.

1888

Ultimas poesias liricas, México, Imprenta de Ignacio Escalante, edición de 150 ejemplares. viii, 216 páginas.

1892

Diana, escrito en 1851, México, Imprenta Ignacio Escalante, edición de 50 ejemplares. 112 páginas. (Con un corto prólogo " $\mathrm{A}$ don Rafael Delgado". Publicado después del mes de julio.)

1895

Ultimas poesías líricas, apéndice hasta mediados de 1895, México, Imprenta de Ignacio Escalante, edición de 150 ejemplares. 104 páginas. (Con un prólogo de "El autor al lector" en que figuran tres cartas de Menéndez y Pelayo a Roa Bárcena. Impreso después del 30 de junio.)

1908

Muerte de don José María Roa Bárcena en la ciudad de México, a las nueve y cuarto de la mañana del 21 de septiembre.

1909

Flores de mayo, o sea el mes de María, segunda edición, México. (Según el obispo Montes de Oca, en la introducción de las Obras poéticas de Roa Bárcena, 1913, p. 82.)

Obras poéticas, publícanlas sus hijas con una Introducción por don Ignacio Montes de Oca y Obregón, Obispo de San Luis Potosi, tomo I, Méjico, Imprenta I, Escalante, S. A. Edición completa de 200 ejemplares numerados. 742 páginas. (Apareció después del mes de abril.)

Renato Rosaldo, Universidad de Illinois, Urbana, Illinois. 


\section{NOTAS}

1 La Cruz, México, Imprenta de J. M. Andrade y F. Escalante, 1856. tomo III, pp. 538-542.

2 José Maria Roa Bárcena, Obras poéticas. Introducción por don Ignacio Montes de Oca y Obregón, tomo I, Méjico, Imprenta de I. Escalante, S. A., 1913 , p. 82 .

3 José Maria Roa Bárcena, Poesías liticas, edición de "La Sociedad", México, Imprenta de Andrade y Escalante, 1859, p. 7.

4 La Sociedad, tercera época, tomo $V, N^{\circ} 748$, lunes 10 de julio de 1865 , p. 3 .

5 Ibid, tercera época, tomo VI, No 1111, miércoles 11 de julio de 1866, p. 3 .

6 Diccionario enciclopédico hispano-americano de literatura, ciencias y artes, tomo XXV, apéndice, Barcelona, Montaner y Simón, Editores, 1899, p. 855 .

7 Enciclopedia universal ilustrada europeo-americana, tomo LI, Madrid. Espasa-Calpe, S. A'., 1926, p. 944.

8 Julio Cejador y Frauca, Histotia de la lengua y literatura castellana comprendidos los autores hispano-americanos, tomo VIII, Madrid, Tip. de la "Revista de Archivos, Bibl. y Museos", 1918, p. 245.

9 Estelle Lutrel1, Mexican Writers, Tucson, Arizona, 1920, pp. 50-51.

10 S. L. Millard Rosenberg, "La prosa mexicana", en Hispania, Stanford University, California, vol. XIII, 1930, p. 16.

11 Julio Jiménez Rueda, Antología de la prosa en México, México, Publicaciones de la Universidad Nacional, 1931, p. 145; así como también en la p. 283 de la segunda edición de dicha obra que publicara Botas en México en 1938 .

12 José María Roa Bárcena, Relatos, Selección y prólogo de J. Jiménez Rueda, Ediciones de la Universidad Nacional Autónoma, México, Biblioteca del Estudiante Universitario, 28, 1941, p. xviii.

13 Victoriano Agüeros, Escritores mexicanos contemporáneos, México, Imprenta Ignacio Escalante, 1880, p. 70.

14 Carlos González Peña, Historia de la literatura mexicana, México, Publicaciones de la Secretaría de Educación Pública, 1928, p. 301; y también 
en la p. 166 de la segunda edición que dieron a la estampa las Editoriales Cvltvra y Polis, S. A, en 1940.

15 Arturo Torres-Rioseco y Ralph E. Warner, Bibliogtafía de la poesía mexicana, Cambridge, Mass., Harvard University Press, 1934, p. 74.

16 Werner Peiser, "El humanismo en la literatura mexicana", en la Revista Iberoamericana, tomo IV, $\mathrm{N}^{9} 8,15$ de febrero de 1942, México, D. F.. p. 377 . 
